with recurrent seizures during phenobarbital therapy, plasma concentrations were predicted to be $<20 \mathrm{mg} / \mathrm{L}$ at the moment of recurrent seizures. This supports a minimal effective concentration of about $20 \mathrm{mg} / \mathrm{L}$.

Conclusion Also during hypothermia we advise an initial 20 $\mathrm{mg} / \mathrm{kg}$ loading dose. However, clinicians should not be reluctant to administer an additional dose of $10-20 \mathrm{mg} / \mathrm{kg}$, as we have shown that the blood levels were often below the therapeutic range $(20-40 \mathrm{mg} / \mathrm{L})$.

\section{EARLY LIPID AND HIGH DOSE AMINO ACID ADMINISTRATION INCREASES ANABOLISM IN VLBW INFANTS}

doi:10.1136/archdischild-2012-302724.0132

${ }^{1} \mathrm{H}$ Vlaardingerbroek, ${ }^{2} \mathrm{CHP}$ van den Akker, ${ }^{1} \mathrm{KY}$ Dorst, ${ }^{1,3} \mathrm{H}$ Schierbeek, ${ }^{3,4} \mathrm{JB}$ van Goudoever. 'Pediatrics, Division of Neonatology; ${ }^{2}$ Pediatrics, Erasmus MC - Sophia Children's Hospital, Rotterdam; ${ }^{3}$ Pediatrics, Academic Medical Center - Emma Children's

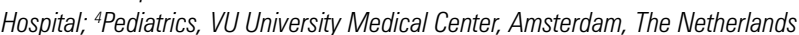

Introduction The beneficial effects of early nutrition in preterm infants are well known. Nonetheless, almost all VLBW infants $(B W<1500 \mathrm{~g})$ develop a protein and energy deficit in the first week of life. Consequently, protein balance is impaired. Lipids could aid in ameliorating the protein balance.

We hypothesized that early parenteral lipid and high dose amino acid (AA) administration from birth onwards to VLBW infants is safe and results in a higher protein balance.

Methods Inborn VLBW infants were randomized to one of three different parenteral nutritional regimens (Figure).

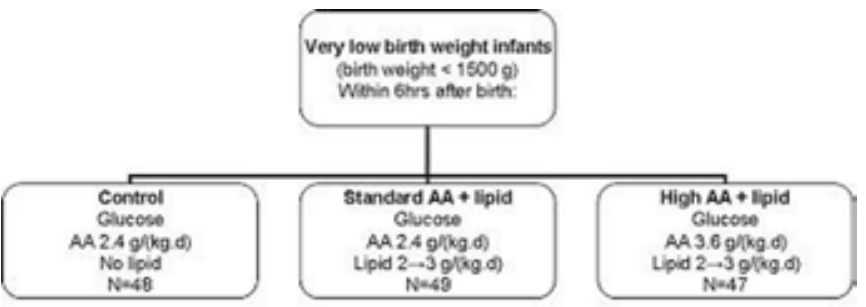

Abstract 132 Figure 1

Nitrogen $(\mathrm{N})$ balances and urea rate of appearance ([urea]Ra, subgroup of infants) were measured at day two; biochemistry was recorded daily.

Results Table shows significant differences at day 2.

Abstract 132 Table 1

\begin{tabular}{llll}
\hline & Control group & Standard AA + lipid & High AA + lipid \\
\hline Glucose $(\mathrm{mmol} / \mathrm{l})$ & $5.5 \pm 2.5$ & $7.0 \pm 2.9 \mathrm{a}$ & $6.6 \pm 3.1$ \\
Urea $(\mathrm{mmol} / \mathrm{l})$ & $10.0 \pm 4.3$ & $8.3 \pm 2.5 \mathrm{a}$ & $11.7 \pm 3.2 \mathrm{~b}$ \\
Triglyceride $(\mathrm{mmol} / \mathrm{l})$ & $0.8 \pm 0.5$ & $2.0 \pm 1.6 \mathrm{a}$ & $1.8 \pm 1.0 \mathrm{a}$ \\
N-balance $(\mathrm{mg} / \mathrm{kg} / \mathrm{d})$ & $93 \pm 111$ & $181 \pm 111 \mathrm{a}$ & $251 \pm 145 \mathrm{a}$ \\
[Urea]Ra $(\mu \mathrm{mol} / \mathrm{kg} / \mathrm{h})^{*}$ & $361(202-520)$ & $413(233-593)$ & $721(197-1245) \mathrm{ab}$ \\
\hline
\end{tabular}

a: sign. different from control group ( $p<0.05)$; b: sign. different from Standard $A A+l i p i d$ group $(\mathrm{P}<0.05) ;{ }^{*}$ median (IQR)

Biochemistry, N-balance and [urea]Ra at day 2

Blood gas, platelet count, electrolytes, and bilirubin were not significantly different between groups.

Conclusion Introduction of $2 \mathrm{~g}$ lipids/(kgd) and $3.6 \mathrm{~g} \mathrm{AA} /(\mathrm{kg} \cdot \mathrm{d})$ from birth onwards seems safe and results in a higher $\mathrm{N}$-balance and thus increased anabolism in VLBW infants. Urea is more likely a marker of AA metabolism than of AA intolerance.

\section{PHYSIOLOGY OF THE AIRWAY AND ITS CONTROL}

doi:10.1136/archdischild-2012-302724.0133

AA Hutchison. University of South Florida, Tampa, FL, USA

Nature, Key Functions, Neural Control \& Clinical Impact.

The airway is a dynamic conduit, extending from the nose to the air sacs. Its key functions include protection, volume maintenance and ventilation, which are coordinated with other motor acts. Neural control of motor output provides airway defense as a first priority, with rapid protection of the lower airway being afforded by laryngeal closure and central apnea. During breathing, stability of airway volume (patency) and gas flow with ensuing gas exchange are also controlled centrally via coordination of motor activities that interact with physiochemical (structural) mechanisms. Sensors rapidly relay information about all key motor functions and, if required, this monitoring results in within-breath pattern adaptations. Neural control of the airway is not only dynamic but varied, with many motor output patterns noted during development and in different physiological (e.g. sleep) and pathological states. The clinician uses this knowledge to interpret breathing patterns as normal or abnormal, and uses this synthesis to direct both investigation of the airway and/or its central control and therapy.

Review aims This talk will describe

- nasal functions for protection and airway patency

- obstructive sleep apnea and the effects of CPAP therapy

- coordination of sucking, nutritive and non-nutritive swallowing in breathing

- laryngeal muscle functions in eupnea, sighs, grunting, incremental breathing and gasping

- lower airway patency and hysteresis matching of conducting and parenchymal airways

- central control of breathing and the impact of changes in breathing with behavioral state

\section{OBSTRUCTIVE SLEEP APNEA, HYPERTONUS AND ADIPOSITAS}

doi:10.1136/archdischild-2012-302724.0134

A Wiater. Hospital Porz am Rhein, Cologne, Germany

Obstructive sleep apnea (OSA) is characterized by prolonged partial and/or intermittent complete (apnea) or partial (hypopnea) upper airway obstructions. The disruption of normal ventilation can be associated with hypoxemia and abnormal sleep patterns. OSA occurs predominantly during REM-sleep. Most affected children present with snoring and breathing problems during sleep.

The prevalence of OSA in children is approximately 4\%. OSA can be associated with daytime sleepiness and cognitive/behavioral complications like poor school performance and hyperactivity. Cardiovascular complications include pulmonary hypertension, cor pulmonale, and systemic hypertension. There is a significant association between apnea-/hypopnea-index (AHI) and oxygen desaturation index with raised daytime and nocturnal blood pressure.

There is an increasing prevalence of obesity in children. Obesity can interfere with sleep in different ways. A lack of sleep is associated with an increased risk for obesity. On the other hand, obesity can have a negative influence on sleep. An increased soft tissue mass and altered mechanics lead to an increased airflow resistance, causing upper airway obstruction. With the current epidemic of obesity the incidence of OSA due to obesity in younger children may become remarkable. The risk for systemic hypertension caused by obesity is independent from the risk for hypertension caused by obstructive sleep apnea. 
Insofar, blood pressure and sleep-related breathing should be monitored beginning with an obstructive AHI of 3/hour sleep. Children with OSA should be treated early enough. Prevention and early treatment of obesity as a risk factor for OSA as well as for hypertension is becoming an important social challenge.

\section{VENTILATORY SUPPORT IN PATIENTS WITH CENTRAL HYPOVENTILATION SYNDROME (CHS) - RESULTS OF THE EU-CHS NETWORK SURVEY}

doi:10.1136/archdischild-2012-302724.0135

${ }^{1} \mathrm{M}$ Migdal, ${ }^{2 \mathrm{H}}$ Trang, ${ }^{3} \mathrm{~J}$ Peters, ${ }^{4} \mathrm{M}$ Katz-Salamon, ${ }^{5} \mathrm{G}$ Ottonello, ${ }^{6} \mathrm{M}$ Samuels. ${ }^{1}$ Children's Memorial Health Institute, Warsaw, Poland; 'Hopital Robert Debre, Paris, France; ${ }^{3}$ Klinikum Dritter Orden, Munich, Germany; ${ }^{4}$ Karolinska Institutet, Stockholm, Sweden; ${ }^{5} G$ Gaslini Institute, Genoa, Italy; ${ }^{6}$ University Hospital of North Staffordshire, Stoke on Trent, UK

Background and aim of the study Aim of the study was to identify the European centers for diagnosis and treatment of patients with CHS and to collect information on type of ventilatory support currently used for this group of patients.

Method The survey was performed in countries participating in the EU-CHS network project. Using a special template following information were collected: total number of already diagnosed patients, number of currently treated patients, type of ventilatory support (invasive ventilation via tracheostomy, mask ventilation, diaphragm pacing, negative ventilation).

Results The survey was performed during 2011. Replies were received from 15 centers located in 10 European countries. Number of CHS patients already diagnosed and currently treated varies significantly between centers (from 2 to 112 and from 1 to 70 respectively). Total number of already diagnosed CHS patients were 305 and 199 of them are currently treated. Most frequently used type of ventilator support is ventilation via tracheostomy ( $52 \%$ of patients). Diaphragm pacing alone or diaphragm pacing and ventilation is currently used in 42 patients. Only one CHS patient is currently treated with negative pressure ventilation.

Conclusions Results of this study have shown existing significant differences (mainly number of patients) but also some similarities (type of ventilatory support) between centers for CHS diagnosis and treatment located in 10 different European countries. All of the collected data should be used for further work on the European CHS network of reference centers.

The study was supported by the EU-CHS Network (grant number 200812 06).

\section{SPONTANEOUS BREATHING PATTERNS OF TRANSITIONING PRETERM INFANTS IN THE DELIVERY ROOM (DR) AND INTERACTIONS WITH MANUAL POSITIVE PRESSURE VENTILATION}

doi:10.1136/archdischild-2012-302724.0136

${ }^{1,2,3} \mathrm{G}$ Schmölzer, ${ }^{2} \mathrm{~J}$ Kaufman, ${ }^{2,4} \mathrm{O}$ Kamlin, 2,4p Davis. ${ }^{1}$ Department of Pediatrics, University of Alberta, Edmonton, AB, Canada; ${ }^{2}$ Neonatal Services, The Royal Women's Hospital, Melbourne, VIC, Australia; ${ }^{3}$ Department of Paediatrics, Medical University of Graz, Graz, Austria; 'Dept. of Obstetrics \& Gynaecology, The University of Melbourne, Melbourne, VIC, Australia

Background Positive pressure ventilation (PPV) remains the cornerstone of respiratory support after birth. Effectiveness of PPV in the DR may be compromised by leak, obstruction and inappropriate tidal volume $\left(\mathrm{V}_{\mathrm{T}}\right)$ delivery.

Aim Describe leak, obstruction and $\mathrm{V}_{\mathrm{T}}$ during spontaneous breathing amongst preterm infants transitioning in the DR and interaction of these breaths with mask ventilation.

Methods Patients were enrolled from the control arm of a randomised trial investigating the use of a respiratory function monitor
(RFM) in the DR; infants $<32$ weeks who were stabilised by paediatric trainees unaware of RFM data were included. During spontaneous breathing on mask continuous positive airway pressure (CPAP) and the delivery of PPV, airway pressures, gas flow and $\mathrm{V}_{\mathrm{T}}$ were recorded. Data were analysed by breath type.

Results In 29 infants, a total of 3864 inflations (mechanical) and inspirations (infant breaths) were analysed (Table 1). Overall mask leak was highest during spontaneous inspirations occurring between manual inflations and those during CPAP. The average $V_{T}$ was highest during combined inspiration and inflation.

Abstract 136 Table 1 Type of Inflation/Breath

\begin{tabular}{|c|c|c|c|}
\hline & Number of Inflations & Mask Leak (\%) & Tidal volume $(\mathrm{mL} / \mathrm{kg})$ \\
\hline Manual Inflation & 2055 (53\%) & $41(32-53)$ & $8.2(6.1-10.7)$ \\
\hline Assisted Inflation & $335(9 \%)$ & $61(46-81)$ & $9.3(4.5-12.6)$ \\
\hline $\begin{array}{l}\text { Spontaneous breath during } \\
\text { PPV }\end{array}$ & $181(5 \%)$ & $92(65-100)$ & $2.9(2.1-4.3)$ \\
\hline $\begin{array}{l}\text { Spontaneous breath while } \\
\text { on CPAP }\end{array}$ & $1285(33 \%)$ & $66(41-100)$ & $4.4(2.5-6.2)$ \\
\hline
\end{tabular}

Conclusion Preterm infants are active participants in stabilisation in the DR. $V_{\mathrm{T}}$ and mask leak vary depending on the interaction between the infant's breathing efforts and the inflations provided by the resuscitator.

\begin{tabular}{l|l}
\hline 137 & HIGH FLOW NASAL CANNULAE (HFNC) OR NASAL \\
CONTINUOUS POSITIVE AIRWAY PRESSURE (NCPAP) \\
POST-EXTUBATION IN PREMATURE INFANTS? A \\
RANDOMISED CONTROLLED TRIAL
\end{tabular}

doi:10.1136/archdischild-2012-302724.0137

${ }^{1} \mathrm{C}$ Collins, ${ }^{1} \mathrm{JR}$ Holberton, ${ }^{1} \mathrm{C}$ Barfield, ${ }^{2} \mathrm{PG}$ Davis. 'Neonatal Medicine, Mercy Hospital for Women; ${ }^{2}$ Newborn Research, Royal Women's Hospital, Melbourne, VIC, Australia

Background NCPAP facilitates successful extubation. It is unclear whether HFNC are as effective as NCPAP in preventing extubation failure. In addition to an alternative modality of respiratory support HFNC may result in less nasal trauma than NCPAP.

Methods 132 preterm ventilated infants were randomised and stratified by gestation (< 28 vs $28-32$ weeks). Primary outcome was extubation failure defined by a composite of 3 pre-specified failure criteria in the 7 days post-extubation. Individual failure criteria were not mutually exclusive and are defined; Apnoea, $>6$ episodes in 6 hours or 1 requiring IPPV, Acidosis, $\mathrm{pH}<7.25 \&$ $\mathrm{pCO}_{2}>66 \mathrm{mmHg}$, and $>15 \%$ increase in $\mathrm{FiO}_{2}$ from extubation. A nasal trauma score was adapted from Kaufman [E-PAS 2007:61390].

Results

Abstract 137 Table 1

\begin{tabular}{lll}
\hline & HFNC N=67 & NCPAP N=65 \\
\hline Male n (\%) & $33(49)$ & $41(63)$ \\
Birthweight g mean (SD) & $1123(317)$ & $1105(374)$ \\
Mean Completed Weeks gestation (SD) & $27.9(1.95)$ & $27.6(1.97)$ \\
Failed Extubation in 1st week by Composite Criteria & $15(22)$ & $22(34)$ \\
$\mathrm{n}(\%)$ & $14(21)$ & $17(26)$ \\
Apnoea: >6 in 6hrs or 1 needing IPPV n (\%) & 0 & $3(5)$ \\
Acidosis:pH<7.25 \& pC02 >66mmHg n(\%) & $7(10)$ & $12(18)$ \\
$>15 \%$ increase in Fi02 post-extubation n(\%) & $7(10)$ & $8(12)$ \\
Reintubated in 1st week n(\%) & $3.1(7.2)$ & $11.8(10.7) \quad \quad \quad p<0.001^{*}$ \\
Nasal Trauma Score 1st week mean (SD) & &
\end{tabular}

